\title{
Augmented Reality: A Brand New Challenge for the Assessment and Treatment of Psychological Disorders
}

\author{
Irene Alice Chicchi Giglioli, ${ }^{1}$ Federica Pallavicini, ${ }^{1}$ Elisa Pedroli, ${ }^{1}$ \\ Silvia Serino, ${ }^{1}$ and Giuseppe Riva ${ }^{1,2}$ \\ ${ }^{1}$ Applied Technology for Neuro-Psychology Lab, IRCCS Istituto Auxologico Italiano, 20145 Milan, Italy \\ ${ }^{2}$ Department of Psychology, Catholic University of Milan, 20123 Milan, Italy \\ Correspondence should be addressed to Irene Alice Chicchi Giglioli; alice.chicchi@gmail.com
}

Received 12 December 2014; Accepted 3 February 2015

Academic Editor: Yuri Ostrovsky

Copyright ( 2015 Irene Alice Chicchi Giglioli et al. This is an open access article distributed under the Creative Commons Attribution License, which permits unrestricted use, distribution, and reproduction in any medium, provided the original work is properly cited.

\begin{abstract}
Augmented Reality is a new technological system that allows introducing virtual contents in the real world in order to run in the same representation and, in real time, enhancing the user's sensory perception of reality. From another point of view, Augmented Reality can be defined as a set of techniques and tools that add information to the physical reality. To date, Augmented Reality has been used in many fields, such as medicine, entertainment, maintenance, architecture, education, and cognitive and motor rehabilitation but very few studies and applications of AR exist in clinical psychology. In the treatment of psychological disorders, Augmented Reality has given preliminary evidence to be a useful tool due to its adaptability to the patient needs and therapeutic purposes and interactivity. Another relevant factor is the quality of the user's experience in the Augmented Reality system determined from emotional engagement and sense of presence. This experience could increase the AR ecological validity in the treatment of psychological disorders. This paper reviews the recent studies on the use of Augmented Reality in the evaluation and treatment of psychological disorders, focusing on current uses of this technology and on the specific features that delineate Augmented Reality a new technique useful for psychology.
\end{abstract}

\section{Introduction}

Augmented Reality (AR) is a new technological system that allows inserting virtual contents in the real world in order to run in the same representation and, in real time, enhancing the user's sensory perception of reality [1]. Compared to a virtual reality system characterized by a computer-generated environment that elicits a strong user's experience of "presence" [2,3], an AR system applies virtual and real elements in a real scene augmenting the user's perception of the world.

More precisely, Azuma et al. $[4,5]$ defined an AR platform as a system that [6]

(i) combines real and virtual objects in a real environment,

(ii) runs interactively and in real time,

(iii) registers real and virtual objects with each other.
Furthermore, according to Milgram et al. [7, 8], AR places between reality (real environment) and virtuality (virtual environment) on the reality-virtuality continuum (see Figure 1).

In an AR system, users see an image made up of a real image and virtual elements that are superimposed over it. The addition of virtual elements may also inhibit the perception of real elements by overimposing the virtual elements on the real elements. Nevertheless, the most important aspect in $\mathrm{AR}$ is that the virtual elements provide the real world with remarkable and valuable information. The addiction of virtual elements may involve not only the view but also the hearing, smell, and touch [9].

From the point of view of technology devices, AR can be defined as a set of techniques and tools that allow adding information to the physical reality. Various technologies are used in AR rendering including handheld devices, display 


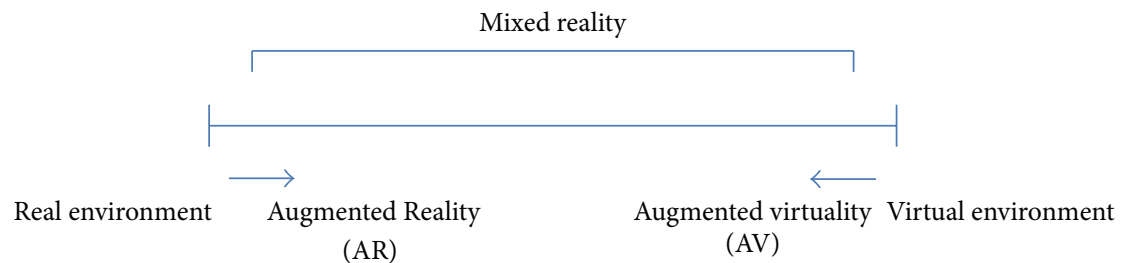

FIGURE 1: It shows a continuum between reality and virtual reality. Mixed reality is located between them and includes Augmented Reality $(\mathrm{AR})$ and augmented virtuality $(\mathrm{AV})$. AR is placed closer to real enviroment than virtual environment.

system worn on one's user (nonhandheld devices), and projection displays.

Modern handheld mobile computing like smartphones and tablets contain these elements, which include a camera and sensors such as accelerometer, Global Positioning System (GPS), and solid-state compass, making them a suitable AR platform. The smartphone or tablet take in real time the surrounding environment and the virtual elements are superimposed to the real world.

An example of nonhandled device is the head mounted display (HMD), a display system worn on one user's head such as a helmet or glasses. HMD systems are characterized by sensors that receive input information about the environment by the user's head movements adding at a later stage various virtual contents.

As regards the projection displays, the virtual elements are projected on the real objects in order to be augmented. The projection occurs with a single room-mounted projector without any display system worn on one user's head. The projector generates a virtual image on the room surface using an automated calibration procedure that takes into account the structure of the surface overlapping the virtual image.

Furthermore, an AR platform requires a software application able to augment the real world by using one or more hardware devices. Marker-based and markerless systems are the two main software applications used in AR system. The AR marker-based systems are stylized pictures in black and white that are recognized by the computer webcam and which are superimposed in real time multimedia contents: video, audio, 3D objects, and so forth. Instead, in the markerless [10] AR system the software application catches the user's positional and orientation data through GPS and compass device adding the virtual contents in an accurate position on or in the real environment.

To date, AR has been used in medicine [11], entertainment [12], maintenance [13], architecture [14], education $[15,16]$, and cognitive $[17,18]$ and motor rehabilitation [19-24] but very few applications of AR exist in clinical psychology and, in particular, it is still underused in the treatment of psychological disorders [25].

Starting from these premises, the aim of this paper is to review the recent studies on the use of $A R$ in the evaluation and treatment of psychological disorders, focusing on current uses of AR in psychology and the various factors that make a new technique useful for the treatment of psychological disorders, expanding the possible fields of use of AR.

\section{Materials and Methods}

We followed the Preferred Reporting Items for Systematic Reviews and Meta-Analysis (PRISMA) guidelines [26].

2.1. Search Strategy. A computer-based search in several databases was performed for relevant publications describing the use of AR in psychology. Databases used for the search were PsycINFO, PubMed/Medline, and Web of Science (Web of Knowledge). We searched using the string "Augmented Reality" AND (psycholog* OR assessment OR treatment). We excluded articles where the full text was not available or where the abstract lacked basic information for review. The first search was performed for publications in the English language, and then we decided to clean the results, considering only publications for the last ten years, from 2004 forward and eventually updated the search results through December 2014. Expert colleagues in the field were contacted for suggestion on further studies not considered in our search.

2.2. Selection Criteria. We have included articles on $A R$ used for psychological settings in assessment or treatment studies. Excluded from the analysis were studies that omitted the inclusion criteria, non-English published studies, review articles, case reports, letters to the editor, research protocols, patents, and editorials. We tried to contact corresponding authors of the included studies with the intent of obtaining incomplete or supplementary data.

2.3. Quality Assessment and Data Abstraction. To assess a risk of bias, PRISMA recommendations for systematic literature analysis have been strictly followed. Three authors (Irene Alice Chicchi Giglioli, Federica Pallavicini, and Silvia Serino) independently selected paper abstracts and titles and analyzed the full papers that met the inclusion criteria, resolving disagreements through consensus.

The data extracted from each included study were sample type, study design, sample size, type of therapy or assessment, and selected findings.

\section{Results and Discussion}

3.1. Systematic Review Flow. The flow chart of the systematic review is shown in Figure 2. Our initial search yielded 918 nonduplicate citations screened via PsycINFO, PubMed/ 


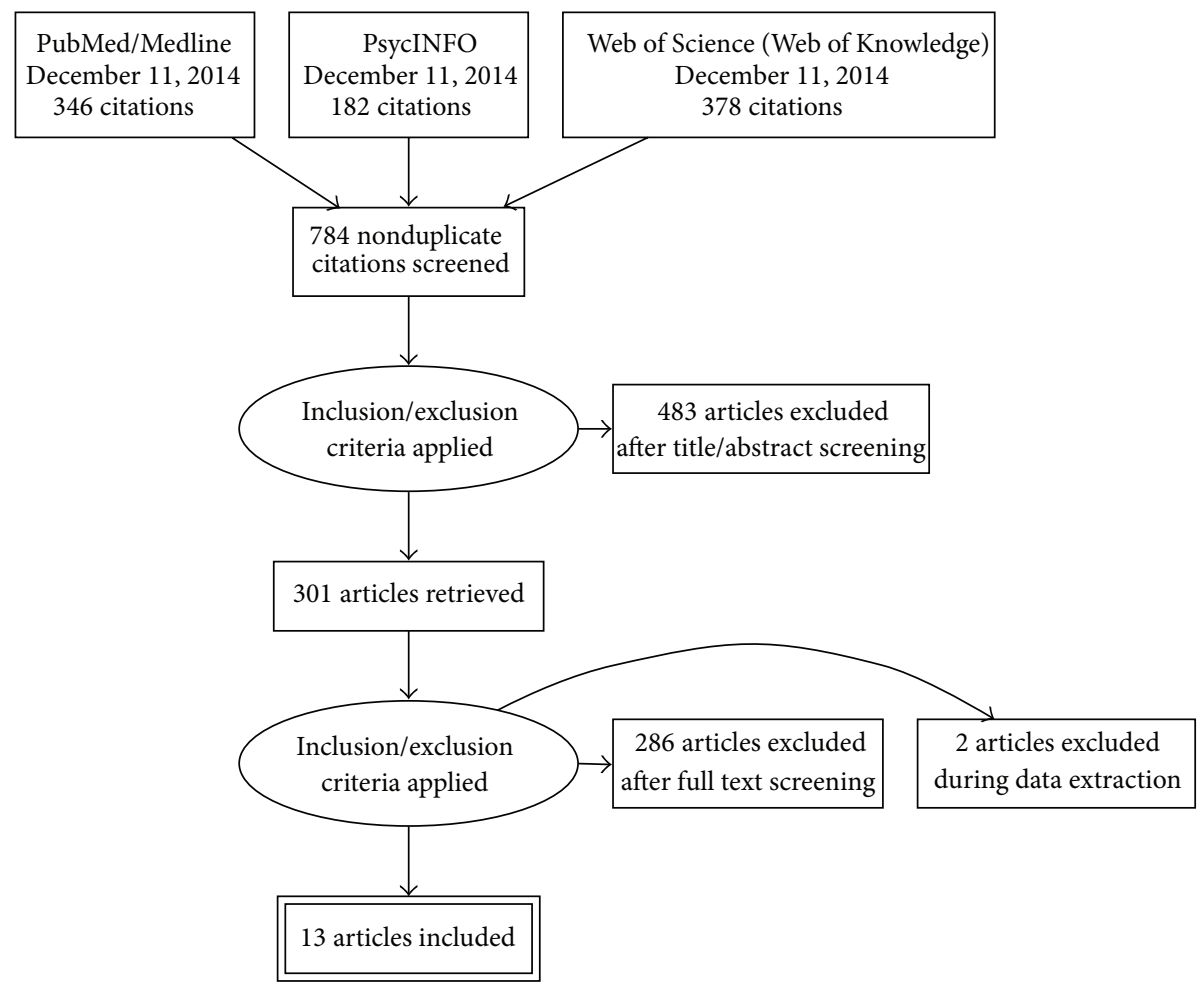

FIgURE 2: Flow diagram of study selection.

TABLE 1: Detailed search strategy.

\begin{tabular}{|c|c|c|c|c|c|}
\hline & "Augmented Reality" and psycholog* & Assessment & Treatment & Other sources & Total \\
\hline Medline & 23 & 56 & 267 & & 346 \\
\hline PsycINFO & 133 & 21 & 28 & & 182 \\
\hline Web of Science (Web of Knowledge) & 69 & 145 & 164 & & 378 \\
\hline Total & 225 & 222 & 459 & 12 & 918 \\
\hline Nonduplicated & 191 & 203 & 378 & 12 & 784 \\
\hline Excluded (after reading title and abstract) & & & & & 483 \\
\hline Retrieved & & & & & 301 \\
\hline Excluded (after applying inclusion criteria) & & & & & 286 \\
\hline Excluded (missing experimental data) & & & & & 2 \\
\hline Included & & & & & 13 \\
\hline
\end{tabular}

${ }^{*}$ is a Jolly characters that means that the search strategy included terms as psychology and/or psychological.

Medline, Web of Science (Web of Knowledge), and other sources: more information is available in Search Strategy and supplement. After the application of inclusion/exclusion criteria, papers have been reduced to 301 articles. A more indepth investigation of the full papers resulted in an exclusion of 286 articles. During the data extraction procedure, 2 additional full papers were excluded. In the end, 13 studies met full criteria and were included in this review (see Table 1).

3.2. Selected Studies on Augmented Reality. Despite a large volume of studies on AR, little has been done specifically to psychological assessment or treatment. In the current review we present a broad range of experimental and clinical studies.
3.3. Results. In the area of clinical psychology, a few but remarkable studies have met the DSM-IV-TR criteria [27], showing the usefulness of AR in the treatment of a specific phobia. More specifically, the review of the literature showed that the phobia of small animals (cockroaches and spiders) and the acrophobia [28-38] are the current areas that used $\mathrm{AR}$ in the assessment and treatment of specific psychological disorders. For the readability of the contents, we have divided the results section in two paragraphs based on specific phobia's typology. The studies are presented in chronological order for showing the developments and advancements that occurred in the use of AR in this area. In addition, the selected final studies can be found in Tables 2 and 3. Each of them is described below. 
TABLE 2: Information about the selected studies on the assessment and treatment of specific phobia for small animals using an AR system.

\begin{tabular}{|c|c|c|c|c|c|c|}
\hline Authors & Year & Sample & Conditions & $\begin{array}{c}\text { Dependent } \\
\text { variables }\end{array}$ & AR device & Results \\
\hline Juan et al. [39] & 2004 & $\begin{array}{c}1 \text { patient with } \\
\text { cockroach phobia }\end{array}$ & $\begin{array}{c}\text { Case study } \\
\text { with AR }\end{array}$ & Anxiety & $\begin{array}{l}\text { HMD with } \\
\text { AR-tags }\end{array}$ & $\begin{array}{c}\text { Decrease of anxiety level } \\
\text { after treatment }\end{array}$ \\
\hline $\begin{array}{l}\text { Botella et al. } \\
{[35,40]}\end{array}$ & 2005 & $\begin{array}{l}1 \text { patient with } \\
\text { cockroach phobia }\end{array}$ & $\begin{array}{l}\text { Case study } \\
\text { with AR }\end{array}$ & $\begin{array}{c}\text { Avoidance } \\
\text { behaviour } \\
\text { Degree of belief in } \\
\text { catastrophic } \\
\text { thought } \\
\text { Anxiety } \\
\text { Target behaviour } \\
\text { Presence } \\
\text { Reality judgment }\end{array}$ & $\begin{array}{l}\text { HMD with } \\
\text { AR-tags }\end{array}$ & $\begin{array}{l}\text { Decrease of anxiety, fear, } \\
\text { and avoidance after } \\
\text { treatment } \\
\text { High level of presence and } \\
\text { judgment of reality }\end{array}$ \\
\hline Juan et al. [31] & 2005 & $\begin{array}{l}9 \text { patients with } \\
\text { cockroach and } \\
\text { spider phobia }\end{array}$ & $\mathrm{AR}$ & $\begin{array}{c}\text { Anxiety } \\
\text { Fear } \\
\text { Avoidance } \\
\text { behaviours } \\
\text { Presence } \\
\text { Reality judgment }\end{array}$ & $\begin{array}{l}\text { HMD with } \\
\text { AR-tags }\end{array}$ & $\begin{array}{l}\text { Decrease of anxiety, fear, } \\
\text { and avoidance after } \\
\text { treatment } \\
\text { High level of presence and } \\
\text { judgment of reality }\end{array}$ \\
\hline $\begin{array}{l}\text { Botella et al. } \\
{[34]}\end{array}$ & 2010 & $\begin{array}{l}6 \text { patients with } \\
\text { cockroach phobia }\end{array}$ & AR & $\begin{array}{c}\text { Anxiety } \\
\text { Target behaviour } \\
\text { Behavioural } \\
\text { avoidance }\end{array}$ & $\begin{array}{l}\text { HMD with } \\
\text { AR-tags }\end{array}$ & $\begin{array}{l}\text { Decrease of anxiety, fear, } \\
\text { and avoidance after } \\
\text { treatment and maintained } \\
\text { at follow-up periods (three, } \\
\text { six, and twelve months } \\
\text { follow-up) }\end{array}$ \\
\hline $\begin{array}{l}\text { Bretón-López } \\
\text { et al. [32] }\end{array}$ & 2010 & $\begin{array}{l}6 \text { patients with } \\
\text { cockroach phobia }\end{array}$ & $\mathrm{AR}$ & $\begin{array}{c}\text { Anxiety } \\
\text { Presence } \\
\text { Reality judgment }\end{array}$ & $\begin{array}{l}\text { HMD with } \\
\text { AR-tags }\end{array}$ & $\begin{array}{c}\text { Decrease of anxiety. High } \\
\text { levels of presence and } \\
\text { reality judgment }\end{array}$ \\
\hline $\begin{array}{l}\text { Botella et al. } \\
\text { [33] }\end{array}$ & 2011 & $\begin{array}{l}1 \text { patient with } \\
\text { cockroach phobia }\end{array}$ & $\begin{array}{l}\text { Case Study } \\
\text { with AR }\end{array}$ & $\begin{array}{c}\text { Anxiety } \\
\text { Target behaviours } \\
\text { Behavioural } \\
\text { avoidance }\end{array}$ & $\begin{array}{c}\text { Mobile phone } \\
\text { marker less } \\
\text { versus HMD } \\
\text { AR-tags }\end{array}$ & $\begin{array}{l}\text { Decrease of anxiety, fear, } \\
\text { and avoidance behaviours } \\
\text { in both conditions. }\end{array}$ \\
\hline $\begin{array}{l}\text { Juan and } \\
\text { Calatrava [37] }\end{array}$ & 2011 & $\begin{array}{l}24 \text { healthy } \\
\text { volunteers }\end{array}$ & $\begin{array}{l}\text { AR-OST } \\
\text { HMD } \\
\text { AR-VST }\end{array}$ & $\begin{array}{l}\text { Anxiety } \\
\text { Presence }\end{array}$ & $\begin{array}{l}\text { AR-OST } \\
\text { HMD versus } \\
\text { AR-VST }\end{array}$ & $\begin{array}{l}\text { The AR-VST induced grater } \\
\text { sense of presence than } \\
\text { AR-OST. } \\
\text { Significant anxiety in both } \\
\text { conditions }\end{array}$ \\
\hline $\begin{array}{l}\text { Juand and } \\
\text { Joele [38] }\end{array}$ & 2011 & $\begin{array}{l}24 \text { healthy } \\
\text { volunteers }\end{array}$ & $\begin{array}{c}\text { AR } \\
\text { marker-based } \\
\text { versus } \\
\text { invisible } \\
\text { AR-tags }\end{array}$ & $\begin{array}{l}\text { Anxiety } \\
\text { Presence }\end{array}$ & $\begin{array}{l}\text { HMD with } \\
\text { visible } \\
\text { AR-tags } \\
\text { versus } \\
\text { invisible } \\
\text { AR-tags } \\
\end{array}$ & $\begin{array}{l}\text { The invisible AR-tags } \\
\text { induced a higher sense of } \\
\text { presence and anxiety than } \\
\text { the visible AR-tags }\end{array}$ \\
\hline $\begin{array}{l}\text { Wrzesien et al. } \\
{[29]}\end{array}$ & 2011a & $\begin{array}{l}22 \text { patients with } \\
\text { cockroach and } \\
\text { spider phobia }\end{array}$ & $\begin{array}{c}\text { In vivo versus } \\
\mathrm{AR}\end{array}$ & $\begin{array}{c}\text { Anxiety, } \\
\text { behavioural } \\
\text { avoidance Belief in } \\
\text { negative thoughts }\end{array}$ & $\begin{array}{l}\text { HMD with } \\
\text { AR-tags }\end{array}$ & $\begin{array}{l}\text { Decrease of anxiety, fear, } \\
\text { avoidance behaviours, and } \\
\text { belief in negative thoughts }\end{array}$ \\
\hline $\begin{array}{l}\text { Wrzesien et al. } \\
{[28]}\end{array}$ & $2011 \mathrm{~b}$ & $\begin{array}{l}22 \text { patients with } \\
\text { cockroach and } \\
\text { spider phobia }\end{array}$ & $\mathrm{AR}$ & $\begin{array}{c}\text { Anxiety, } \\
\text { behavioural } \\
\text { avoidance Belief in } \\
\text { negative thoughts }\end{array}$ & $\begin{array}{l}\text { HMD with } \\
\text { AR-tags }\end{array}$ & $\begin{array}{l}\text { Decrease of anxiety, fear, } \\
\text { avoidance behaviours, and } \\
\text { belief in negative thoughts }\end{array}$ \\
\hline $\begin{array}{l}\text { Wrzesien et al. } \\
{[30]}\end{array}$ & 2013 & $\begin{array}{l}26 \text { healthy } \\
\text { volunteers }\end{array}$ & AR & $\begin{array}{l}\text { Anxiety } \\
\text { Avoidance }\end{array}$ & $\begin{array}{l}\text { Therapeutic } \\
\text { lamp (TL) }\end{array}$ & Decrease of anxiety \\
\hline
\end{tabular}

3.4. AR and Specific Phobia for Small Animals. In the studies, the AR exposure therapy was based on Öst et al.'s "one-session treatment" guidelines [41, 42]. Individuals make one single intensive exposure session that lasts up to three hours.
The first analysed study that used an AR system to assess and treat specific phobias was conducted by Juan et al. (2004) [39]. A single individual with cockroach phobia [27] was assessed using an HMD-AR system. The AR device used 
TABLE 3: Information about the selected studies on the assessment of acrophobia using an AR system.

\begin{tabular}{|c|c|c|c|c|c|c|}
\hline Authors & Year & Sample & Conditions & $\begin{array}{c}\text { Dependent } \\
\text { variables }\end{array}$ & AR device & Results \\
\hline $\begin{array}{l}\text { Juan et al. } \\
{[43]}\end{array}$ & 2006 & $\begin{array}{l}41 \text { healthy } \\
\text { volunteers }\end{array}$ & $\begin{array}{c}\text { Real environment } \\
\text { versus AR } \\
\text { environment }\end{array}$ & $\begin{array}{l}\text { Sense of } \\
\text { presence }\end{array}$ & AR-HMD & $\begin{array}{l}\text { High sense of presence in } \\
\text { the AR environment }\end{array}$ \\
\hline $\begin{array}{l}\text { Juan and Prez } \\
{[36]}\end{array}$ & 2010 & $\begin{array}{l}20 \text { healthy } \\
\text { volunteers }\end{array}$ & $\begin{array}{l}\text { AR system versus } \\
\text { VR system }\end{array}$ & $\begin{array}{l}\text { Sense of } \\
\text { presence } \\
\text { Anxiety }\end{array}$ & $\begin{array}{l}\text { HMD-AR } \\
\text { with tags } \\
\text { VR-HMD }\end{array}$ & $\begin{array}{c}\text { In regard to sense of } \\
\text { presence and anxiety levels, } \\
\text { AR is effective as VR }\end{array}$ \\
\hline
\end{tabular}

was an HMD system connected with a camera and a PC. The camera, placed on the HMD, recognized the marker through the movement of the subject's head, projecting the virtual cockroaches in front of the subject. The AR single exposure session consisted progressively in seeing, touching, and finally killing one or more virtual cockroaches. The therapist chose in any moment how many cockroaches had to appear on the scene, their size, and if they had to move or not. During the treatment, the augmented cockroaches were able to arouse anxiety in patient that decreased after an hour of exposure. More specifically, before, during, and after treatment, the patient ranked her level of anxiety on a 10 -point scale (where 0 represents no anxiety and 10 very high anxiety) using the Subjective Units of Discomfort Scale (SUDS) [44]. The data showed a decrease in anxiety score after exposure (with a score of 10 on SUDS at the beginning of the session and a score of 0 after the session) and clinical improvements regarding patient's phobia. In particular, after exposure, the patient was able to approach, interact, and kill real cockroaches.

Botella et al. (2005) [35] assessed a cockroach phobia case study [27] using an HMD-AR system developed for this specific disorder. The AR device used was an HMD system connected with a camera and a PC. The camera, placed on the $\mathrm{HMD}$, recognized the marker through the movement of the subject's head, projecting the virtual cockroaches in front of the subject. The AR system included the possibility for the therapist to choose the number of cockroaches, their size, and movements and for the patient to kill one or more cockroaches using two different instruments, a fly swatter or a cockroach killer. Depending on the selected tool the system played a sound analogous to the real one. In order to assess the intensity of the phobia, the behaviour avoidance test (BAT) [42], degree of belief in catastrophic thought (assessed daily on scale from $0 \%$ to $100 \%$ ), Fear and Avoidance Scales [45],Fear of Spiders Questionnaire (FSQ) [46], Spider Phobia Beliefs Questionnaire (SPBQ) [47], and Subjective Units of Discomfort Scale (SUDS) [44] were used. Furthermore, in order to assess the degree of presence and reality judgment experienced in the AR session, the authors created specifically for this study one ad hoc questionnaire composed by two questions related to presence: "To what degree have you felt present in the situation?" and "To what degree have you felt that you were in the place where the cockroaches appeared?" and one question for the reality judgment: "To what degree did the cockroaches appear to be real?" After AR exposure, the participant was asked to evaluate these features on a scale from 0 (no degree of being in a place/being real) to 10 (very high degree of being in a place/being real). The results showed that, before the exposure, patient exhibited a considerable fear and avoidance behaviours and after exposure not only were there important decreases in the fear and avoidance scores, but also the patient was able to approach, interact, and kill cockroaches with a high degree of presence and reality judgment. Similarly, at the beginning of the experiment, virtual cockroach induced anxiety in patient but after one hour of exposure the anxiety was significantly declined. Finally, the treatment gains were maintained in a followup conducted two months after the end of the treatment, showing decreases in the various scales of the BAT [42].

Juan et al. (2005) [31], for the first time, evaluated the effectiveness of an AR system not in one single case but in a sample of nine patients with cockroach and spider phobia [27]. The AR system was the same used in the Botella et al. study [35], described previously. The AR exposure involved the gradual appearance of one or more spiders/cockroaches and the possibility for the patients to approach them with hands, to look in boxes in order to simulate when you are searching for a small animal in your house, and to beat and throw away them. With respect to psychological measures, anxiety, fear, and avoidance behaviours were assessed using Fear and Avoidance Scales [45] and SUDS [44]. The degree of presence and reality judgment experienced by the users in the AR system were assessed using three ad hoc questions, created specifically for this study. The three questions were "To what degree have you felt present in the situation?" "To what degree have you felt that you were in a place in which spiders/cockroaches appeared?" And "To what degree did you think the spiders/cockroaches were real?" Participants were asked to evaluate these features in a scale from 0 to 10 (where 0 represents the lowest degree of being in a place/ being real and 10 the highest degree of being in a place/being real). The results showed that the treatment produced a decrease in the patient's fear and avoidance behaviours [45] when they had to face with the target spider/cockroach. Furthermore, as in the study of Botella et al. [35], during the exposure, the participant's anxiety scores (SUDS) [44] were high, but they diminished at the end of the treatment.

In Botella et al. (2010) [34] an AR system was tested in the short and long term (three-, six-, and twelve-month followup) on a sample of six individuals suffering from cockroaches phobia [27]. The AR system was the same as that used in the preceding studies $[31,35]$. Before, during, and after the AR exposure, participants were asked to fill out questionnaires, 
including SUDS [44] to evaluate anxiety levels, BAT [42], FSQ [46], and SPBQ [47] to assess fear and avoidance behaviours. AR exposure has been led in a single extended session lasting up to three hours. Each participant faced with various scenarios, progressing from the easiest to the most difficult situation. For example, at the beginning of the exposure, the program exhibited one cockroach to the participants, and more animals were added progressively. The purpose of the exposure was to interact with many cockroaches repeatedly, touch them, kill them, and remain in the situations until they experienced a considerable decrease in anxiety. As above in Botella et al. (2005), the results showed that AR was effective in treating cockroach phobia, improving significantly in all outcome measures after treatment. More specifically, the AR system, at the beginning of the exposure, was able to induce anxiety in the participants and after treatment produced a significant decrease in the level of fear and avoidance behaviours in all participants. In accordance with the BAT's scores [42], before treatment, none of the participants were able to interact with a real cockroach, while after treatment all participants could approach it. At the same time, also the self-report scores of FSQ [46] and SPBQ [47] improved significantly after treatment. Furthermore, the treatment gains were maintained at three-, six-, and twelve-month follow-up periods. Unlike the study conducted in 2005 by Botella et al. [35], measures related experience has not been recorded.

Bretón-López et al. (2010) [32] evaluated the ability of an AR system to raise anxiety and, secondly, to elicit sense of presence and reality judgment in six participants suffering from cockroach phobia [27]. In the single AR exposure session, participants were exposed to various stimuli, based on each individual's hierarchy of fears (from one static insect to the one in movement, from more static insects to ones in movement, and from insects next to personal belongings to those next to hands). Moreover, the AR system included the possibility to vary the numbers of cockroaches on the scene and the movement and the size of cockroaches. During and after the AR exposure, patients' level of anxiety was evaluated through the SUDS on a scale of 0 (no anxiety) to 10 (very high anxiety) [44], and the degree of presence through the Presence and Reality Judgment Questionnaire (PRJQ) [48]. The data showed that, at the start of AR immersion, the anxiety levels, measured through the SUDS questionnaire [44], ranged from 9 to 10 (the highest levels of the scale) but they decreased progressively during the exposure. The levels and the duration of exposure needed for anxiety reduction were based on initial levels of fear and on the severity of the phobia. Furthermore, patients showed high scores in the PRJQ [48], representing high levels of presence and reality judgment experienced during the AR exposure.

In 2011, Botella et al. [33] assessed a single cockroach phobia case study [27] testing an AR system using a mobile phone and creating a mobile game, "Cockroach Game" [33] for the treatment of this phobia. The subject conducted three therapeutic phases. In the first phase, the participant was asked to play, as much as she wanted, "Cokroach Game" for nine days and to record her levels of fears, avoidance, and belief in the catastrophic thought using the BAT [42] and FSQ [46]. In the second phase, the participant received the AR exposure treatment, assessing again the psychological measures. In the third phase, the participant was asked to play again the "Cockroach Game" for another period of nine days and recorded the same questionnaire. In this study the experiential measures of presence and reality judgment have not been taken into account. The data showed that before and after the first phase a slight improvement is obtained in performance, fear, and avoidance, whereas there was an increased in the belief in the catastrophic thought. After the AR exposure there were improvements in all BAT measures [42]: performance, fear, avoidance, and belief. After the third phase a significant decrease was obtained in all psychological measures, maintaining them at one, three-, six-, and twelvemonth follow-up periods.

In 2011, Juan and Calatrava [37] compared an AR optical see-through (OST) system with a video see-through (VST) for the treatment of spiders and cockroaches phobia in twenty-four nonphobic participants. Individuals were divided in low and high fear subject's group according to scores in the fear and avoidance of cockroach and spider questionnaires [46] and underwent both experimental conditions. Before, during, and after exposure subjects were asked to rate their level of anxiety from 0 (no anxiety) to 10 (very high anxiety). Presence experienced by participants was assessed using an adapted version of the Slater et al.'s (1994) questionnaire [49]. The six question were "Please rate your sense of being in a room where there are cockroaches/spiders." "To what extent were there times during the experiment when the cockroaches/spiders were real for you?" "When you think back to your experience, do you think of cockroaches/spiders more as images that you saw (a movie, a picture), or more as cockroaches/spiders that were in the same room as you were?" "During the experiment which was strongest on the whole: your sense of being in the room where there were cockroaches/spiders, or your sense of being in a room without cockroaches/spiders?" "Think about your memory of being in a room where there were cockroaches/spiders. How similar is this memory to your memories of other places where there were these animals?" And "During the experiment, did you often think that you were actually in a room where there were cockroaches/spiders?" The scoring was on a scale of 1-7 (where 0 corresponds to not being in a place and 7 represents the normal experience of being in a place). Results showed that the VST system induced a higher sense of presence than the OST system and the two systems produced similar and significant anxiety before treatment that decreased after exposure.

Juan and Joele (2011) [38] compared an AR visible marker-based system with an AR invisible marker system in twenty-four healthy subjects. Participants rated their intensity of anxiety level from 0 (no anxiety) to 10 (very high anxiety) at eight different moments during the AR exposure. As in the previous study, after each AR exposure, individuals were asked to fill out an adapted Slater et al.s (1994) questionnaire (SUS) [49] to rate the subjective feelings of presence experienced. Results showed that the AR invisible marker system elicited a higher sense of presence compared to the AR visible marker system. Furthermore, at the beginning of the treatment, the AR invisible marker system provokes a higher 
level of anxiety that decreases significantly during and at the end of the AR exposure.

Wrzesien et al. (2001a; 2011b) [28, 29] conducted two studies to evaluate the level of anxiety, avoidance, behavioural avoidance, and belief in negative thoughts in patients with small animal phobia [27].

The first study [29] compared the in vivo exposure therapy with the AR exposure therapy in twenty-two individuals with specific phobia for spiders and cockroaches [27]. The patients were randomly allocated to one of two groups. Before and after the exposure session, the participants were asked to fill out the behaviour avoidance test (BAT) [42]. The data showed that both in vivo and AR exposure are therapeutically effective in reducing anxiety, avoidance, and behavioural avoidance. In particular, the analysis of the pre- and posttest BAT scores showed no statistically significant differences between the in vivo group and the AR exposure group. Furthermore, an intragroup analysis showed a statistically significant decline in the severity of avoidance under both conditions, suggesting that both exposures are effective in the reduction of avoidance behaviours after treatment.

In the second study [28], five patients were assessed and treated using only an AR therapeutic exposure [27]. Before, during, and after the exposure session, the participants were asked to rank their level of anxiety on a scale of 0 (no anxiety) to 10 (very high anxiety), avoidance on a scale of 0 (low degree of avoidance) to 10 (high degree of avoidance), behavioural avoidance on a scale of 0 (low degree of behavioural avoidance) to 13 (very high degree of behavioural avoidance), and belief in catastrophic thoughts on a scale of 0 (low degree of belief) to 10 (high degree of belief). The results showed a posttreatment decrease in level of anxiety, avoidance, and belief in negative thoughts. More precisely, if, before the therapy, patients were unable to get close to live cockroaches, after the treatment they were able to interact with real cockroaches into a terrarium.

In a further study, Wrzesien et al. (2013) [30] experimented with an innovative technological AR system named therapeutic lamp (TL). The TL is an AR display projector created for the treatment of small animals' phobia. The trial included twenty-six healthy volunteers and consisted of one single exposure session composed by twelve exercises progressed from those who induced less anxiety to the ones that elicited more anxiety. For example, at the beginning of the exposure, participants observed three dead and three paralyzed animals and, at the end, they had to kill 30 animals with the flyswatter. In order to measure the participants' experience during the exposure, four clinical instruments were used. The Spider and Cockroach Anxiety and Avoidance Questionnaire was assessed before the session on a scale of 0 (no degree of fear and avoidance) to 7 (high degree of fear and avoidance). The Self-Efficacy Belief Questionnaire was used before and after the exposure session on a scale of 0 (no degree of belief that the participant could confront a real cockroach or spider) to 7 (high degree of belief). The Subjective Units of Discomfort Scale (SUDS) [44] was assessed at the beginning and end of each exercise in the session on a scale to 0 (no anxiety) to 10 (very high anxiety). The Presence and Reality Judgment Questionnaire (PRJQ) [48] was tested at each exercise's start on a scale of 0 (no degree of being in a place/being real) to 10 (high degree of being in a place/being real). The data showed that the participants' anxiety scores, measured by SUDS [44], were high at each exercise's beginning but decreased after the exercise session. In addition, the participant's belief in their capacity to face with the small animals improved significantly after the session. Finally, the PRJQ [48] scores showed that the participants felt the virtual animals' presence relatively well and considered them to be rather real. Therefore, the authors concluded that the AR-TL could be a good and helpful treatment's tool for psychological disorders even if the system has to be validated with patients in future studies.

All these studies represent new potentiality and possibility of assessment and treatment in the area of psychological disorders. However, they disclose some limitations. The majority of the disclosed studies $[28,29,31-35]$ include a too small sample for the experimental validity characterized by patients with specific phobias. Instead, one study [30] focused on testing an innovative AR system with healthy volunteers in order to verify the efficacy, usability, and quality of user's experience of the new platform. Related to the previous consideration, the presented studies [28, 30-35] have not included control groups, experimental controls, or randomized controlled studies. Only one study conducted by Wrzesien et al. (2011a) [29] has performed a randomized controlled study, comparing the in vivo exposure therapy with the AR exposure therapy.

3.5. AR and Acrophobia. In 2006, Juan et al. [43] advanced the use of immersive photography in an AR system to treat acrophobia. For evaluating this system, forty-one healthy volunteers walked around at the top of a staircase in a real environment and using the immersive photography environment. After their experience, the participants filled out the SUS questionnaire [49] to assess their subjective sense of presence. The data showed that the AR condition induced a sense of presence equal to the one experienced by the subjects in the real world.

Another study, conducted by Juan and Prez (2010) [36], compared an acrophobic virtual reality (VR) and AR environment assessing differences in the sense of presence and anxiety elicited by the two systems. Twenty healthy participants underwent both experimental conditions and after using each system (AR or VR), they completed an adapted SUS questionnaire [49]. Moreover, at six different moments during the two experiences, the participants were also asked to rate their anxiety level from 0 (no anxiety) to 10 (very high anxiety). Regarding the sense of presence, the results showed no differences between the two systems. Moreover, data revealed that anxiety levels decrease after the exposure.

3.6. Discussion. In the current scientific scenario, $\mathrm{AR}$ is a relevant issue and offers a viable alternative to traditional methods as the in vivo exposure therapy. This paper is the first systematic review that explores studies in the literature that use AR as a tool in the treatment of psychological disorders. 
To date, the analysis of the literature suggested that AR has been mainly used in the evaluation and treatment of specific phobias such as phobias for small animals (cockroaches and spiders) and acrophobia. Regarding the assessment and treatment of specific phobias, from the literature analysis, it has been observed that thirteen studies have used an AR system in order to reduce anxiety, fear, and avoidance behaviours. Specifically, eleven studies concerned the evaluation and treatment of cockroaches and spiders phobia, while two studies affected the acrophobia.

As regards the cockroaches and spiders phobia, nine studies applied an AR-HMD system connected with a camera and a computer $[28,29,31,32,34,35,37-40]$. The camera was placed on the HMD helmet and connected with a USB to the computer where the AR system ran. The camera, recognizing the marker through the movement of the subject's head, projected the virtual images and objects in front of the subject. Among these studies, two $[37,38]$ compared different AR systems in order to evaluate their efficacy. In particular, Juan and Calatrava (2011) [37] compared an AR optical seethrough (OST) system with a video see-through (VST), and Juan and Joele (2011) [38] contrasted an AR visible markerbased system with an AR invisible marker system.

The last studies have tested two innovative technological AR systems [30, 33]. In 2011, Botella et al. [33] have experimented with a new AR-mobile phone system and have created a mobile game, "Cockroach Game" [33] for the treatment of the cockroach phobia. The Cockroach Game is a puzzle game characterized by different levels of fear stimuli divided in two situations allowing players to progress in the game. The first included the possibility to see animals on various virtual situations inside the mobile phone. The second one allowed seeing them on real environment such as on the hands. In a further study, Wrzesien et al. [30] experiment with an innovative technological AR system, named therapeutic lamp (TL). The TL is an AR display projector created for the treatment of small animals' phobia.

As mentioned above, the majority of the studies concerned the assessment and the treatment of small animals phobias: five studies have focused on patients with cockroaches' phobia $[32-35,39,40]$ and three on the cockroaches and spiders phobia [28, 29, 31] according the DSM-IV [27] criteria. Instead, three studies $[30,37,38]$ have included healthy volunteers without any diagnosis of psychological and medical problems. In most of the studies [28, 29, 31-35], the AR exposure therapy was applied using the "one-session treatment" guidelines developed by Öst $[41,42]$.

A remarkable feature refers to the number of subjects included in these studies and the psychological and experiential measures in the assessment of the AR exposure therapy. Three studies experimented with one case study [33, 35, 39], two studies tested the AR system on six patients [32, 34], and one study assessed nine patients [31]. The remaining five studies have experimented with a higher number of subjects [28-30, 37, 38]. In 2011, Juan et al. [37, 38] assessed twenty-four healthy volunteers, while Wrzesien et al. (2011a; $2011 b ; 2013$ ) [28-30], in the first two studies [28, 29], assessed twenty-two patients and, in the third study [30], they tested twenty-six healthy subjects.
Furthermore, all these studies considered anxiety as psychological measure showing that AR elicits anxiety as soon as the stimulus appeared that decreased during the time of exposure [28-35, 37-39]. Among these studies, seven of them also considered fear and avoidance behaviours showing that AR was able to reduce significantly fear and avoidance behaviours after the stimuli exposure [28-31, 3335]. Finally, as regards the quality of user's experience, five studies measured presence $[31,32,35,37,38]$ and three of them evaluated reality judgment $[31,32,35]$ showing a high sense of presence in the AR system and reality judgment of the small animals.

Taking the two acrophobia studies $[36,43]$ into account, both applied an AR-HMD system to evaluate its efficacy comparing, in the first study, the AR-HMD system with a real environment [43] and, in the second study, the AR-HMD system with a VR- HMD system [36].

Regarding the number of subjects, both of the studies included healthy volunteers and, specifically, in 2006, Juan et al. [43] assessed forty-one participants, while in 2010 they evaluated twenty [36].

Among these studies, just Juan and Prez (2010) [36] considered anxiety as psychological measure showing that AR is effective as VR to induce anxiety when the stimulus appeared, which decreased during the exposure. In conclusion, both studies assessed the sense of presence showing, in the study of 2006 [43], a higher sense of presence in the AR environment than the real environment and in the study of 2010 [36] no difference between the AR and the VR environment.

The studies mentioned above suggest that AR offers many advantages such as the possibility to reproduce real objects in the environment (ecological validity), controlled situations, and ad hoc environments and objects in order to tailor the situations on the subject's needs and therapeutic purposes. However, the discussed studies are mostly preliminary researches that disclose some limitations due to the fact that AR exposure has only been recently tested for the evaluation and treatment of psychological disorders. The majority of the disclosed studies [28, 29, 31-35, 39] include a too small individual's sample and only one [29] of them is based on a randomized controlled design.

Instead, the reaming studies focused on testing the AR system on healthy subjects in order to verify the efficacy, usability, and the quality of user's experience of the new platform using randomized controlled studies [30, 36-38, 43].

Apart from these studies, the literature is lacking studies of $\mathrm{AR}$ on the treatments of other several psychological disorders.

Currently, other technological devices have proven effective in the evaluation and treatment of psychological disorders. In particular, VR has been demonstrated to be a very useful tool for the treatment of several psychological problems such as eating disorders and anxiety disorders [50-54]. The traditional treatment for these psychological disorders is the in vivo exposure therapy. As the term implies, the in vivo exposure therapy allows subjects to experience their fears under the close supervision of a physician or a therapist. However, not all patients benefit from this treatment and, according to Jefferey et al. (2000) [55] and Mann et al. (2007) 
[56], some patients do not improve after treatment and others relapse in the long term.

In the last few years many studies have showed the efficacy of VR environments as therapeutic tool [50-53, 57-60]. A VR environment is a completely simulated three-dimensional environment modelled by a computer that allows, through the simulation, coping with critical and fear situation in a safe condition without losing sensory experience and physical presence.

A feature that makes VR a useful tool for evaluation and treatment of psychological disorders is to elicit emotional responses commensurate with the real ones.

The emotional engagement in virtual exposure depends on a number of factors such as the sense of presence. The sense of presence in virtual exposure is defined as the degree of "being there" in the virtual environment [61] and is marked by the sense of immersion and a sense of interaction. The sense of immersion is the result of the technological tools used such as the use of the HMD device that allows an immersive 3D experience to subjects. Instead, the sense of interaction is defined as the degree of interaction and manipulation for individuals of the virtual content or environment. Therefore, a high sense of presence in a virtual environment provides a greater realistic perception of the experience and consequently a strong and deep emotional engagement. This experience increases the ecological validity of the instrument of VR in the treatment of psychological disorders ensuring, through a simulated environment, a similar experience to the real one. At the same time, the user, feeling "present" in the simulated environment, perceives it as real and tends to transfer the expected skills from the virtual world to the real one in a nearly automatic manner.

Recent studies have shown that virtual exposure is as effective as in vivo exposure [62-64] and, in particular, the exposure to virtual environments has produced emotional and behavioural responses similar to those that occurred in the real world.

In the studies of Ferrer-García and Gutiérrez-Maldonado $[62,63]$ six virtual environments emotionally relevant and significant to subjects with eating disorders (ED) have been realized. Before and after exposure to each virtual environment, they estimated the state of anxiety and depression levels and the data showed that the virtual exposure is effective in causing and provoking relevant emotional responses to subjects.

Gorini et al. [64] started from the two previous studies but compared the virtual stimuli with the real ones and with their correspondent pictures to test the psychological (measuring the level of anxiety and sense of presence) and physiological (measuring the heart and respiration rate and the skin conductance) reactions to food in a sample of ED patients and healthy controls. After each experimental condition, in order to estimate the psychological variations, the subjects carried out two states of anxiety tests (STAI-S and VAS-A) and then the virtual exposure completed the presence questionnaire. The data showed that virtual stimuli are effective as the real one and more than photographs in eliciting emotional responses in ED patients and, more generally, the use of VR instead of real stimuli may simplify the framework of very specific contexts to help patients to cope with their conditions through a very controlled stimulation.

Finally, regarding the sense of presence, the results showed a significant degree of presence on the level of state anxiety in VR and real exposure conditions. As mentioned above, the VR gives the possibility of the subject to manipulate and interact with the environment and contents as in the real world.

Similarly, AR could be considered a useful tool in the evaluation and treatment of psychological disorders providing a number of advantages as the VR. Indeed, the AR, as VR simulation, can be seen as an experiential process, and the experience is an essential component in dealing with critical situations. Furthermore, this experience could allow exploring environments and situations hard to reproduce in reality and, as the VR, the feeling of presence in the AR system could permit the user to assign the learned behaviours from the AR world to the real one.

The AR simulation, therefore, could be considered an efficient method to act on real behaviours avoiding the risks and complications typical of real environments.

\section{Conclusions}

The aim of this paper was to review the recent studies on the use of AR in the evaluation and treatment of psychological disorders, focusing on current uses of AR in psychology and the various factors that make a new technique useful for the treatment of psychological disorders, expanding the possible fields of use of AR.

In general, the presented studies show that the AR seems to be a promising and useful tool for intervention in the treatment of specific phobias. Nevertheless, the small sample of subjects examined and the lack of control group and randomized controlled studies necessitate more randomized controlled experiments for exploring the AR efficacy in the clinical treatments. Despite these limitations, AR is proving to be a new technique useful to patients to experiment with technologically different and severe situations, as the exposure to fear or phobic stimuli, in a safe environment under the control of the therapist. Indeed, an AR system extends interactivity for assessing and supervising patient's reactions in real time and adaptability for creating controlled exposure settings based on the patient's needs or therapeutic purposes. Furthermore, it is to be noted that AR allows subjects/patients to manipulate and control the virtual elements, interacting with virtual objects placed in the real world in real time.

As a consequence, the experience to amplify the physical world with virtual contents can improve the ecological validity of the "mixed reality" [7] on environment, augmenting the sense of presence and engagement of the subject/patient. Indeed, studies of VR have shown that virtual stimuli are comparable to the real stimuli with regard to emotional responses [62-64]. Finally a strong and deep sense of presence and engagement can, also, improve the adherence to treatment.

Overall, AR may represent a new challenge for the assessment and treatment of different kinds of psychological 
disorders, such as eating and anxiety disorders performing new studies based on systematic measures of psychological and neurophysiological effects.

\section{Abbreviations}

$\begin{array}{ll}\text { AR: } & \text { Augmented Reality } \\ \text { BAT: } & \text { Behaviour avoidance test } \\ \text { FSQ: } & \text { Fear of Spiders Questionnaire } \\ \text { GPS: } & \text { Global Positioning System } \\ \text { HMD: } & \text { Head mounted display } \\ \text { OST: } & \text { Optical see-through } \\ \text { PRISMA: } & \text { Preferred Reporting Items for Systematic } \\ & \text { Reviews and Meta-Analysis } \\ \text { PRJQ: } & \text { Presence and Reality Judgment } \\ & \text { Questionnaire } \\ \text { SPBQ: } & \text { Spider Phobia Beliefs Questionnaire } \\ \text { SUDS: } & \text { Subjective Units of Discomfort Scale } \\ \text { TL: } & \text { Therapeutic lamp } \\ \text { VR: } & \text { Virtual reality } \\ \text { VST: } & \text { Video see-through. }\end{array}$

\section{Conflict of Interests}

There is no financial or personal interest to report.

\section{Authors' Contribution}

Irene Alice Chicchi Giglioli, Federica Pallavicini, and Silvia Serino independently selected paper abstracts and titles and analyzed the full papers that met the inclusion criteria, resolving disagreements through consensus. Irene Alice Chicchi Giglioli, Federica Pallavicini, Elisa Pedroli, and Silvia Serino participated in the study design and wrote the paper. Elisa Pedroli, Silvia Serino, and Giuseppe Riva conceived the study and participated in its drafting, design, and coordination. All authors read and approved the final paper.

\section{Acknowledgment}

This work was supported by the Italian funded project "VRehab. Virtual Reality in the Assessment and TeleRehabilitation of Parkinson's Disease and Post-Stroke Disabilities" (RF2009-1472190).

\section{References}

[1] O. Hugues, P. Fuchs, and O. Nannipieri, New Augmented Reality Taxonomy: Technologies and Features of Augmented Environment, Springer, New York, NY, USA, 2011.

[2] G. Riva, F. Davide, and W. A. IJsselsteijn, Eds., Being There: Concepts, Effects and Measurements of User Presence in Synthetic Environment, Studies in New Technologies and Practices in Communication, IOS Press, Amsterdam, The Netherlands, 2003.

[3] G. Riva, J. A. Waterworth, and E. L. Waterworth, "The layers of presence: a bio-cultural approach to understanding presence in natural and mediated environments," Cyberpsychology and Behavior, vol. 7, no. 4, pp. 402-416, 2004.
[4] R. T. Azuma, "A survey of augmented reality," Presence: Teleoperators and Virtual Environments, vol. 6, no. 4, pp. 355-385, 1997.

[5] R. Azuma, Y. Baillot, R. Behringer, S. Feiner, S. Julier, and B. MacIntyre, "Recent advances in augmented reality," IEEE Computer Graphics and Applications, vol. 21, no. 6, pp. 34-47, 2001.

[6] F. Zhou, H. B.-L. Dun, and M. Billinghurst, "Trends in augmented reality tracking, interaction and display: a review of ten years of ISMAR," in Proceedings of the 7th IEEE/ACM International Symposium on Mixed and Augmented Reality ( ISMAR '08), pp. 193-202, IEEE, Cambridge, UK, September 2008.

[7] P. Milgram and F. Kishino, "A taxonomy of mixed reality visual displays," IEICE Transactions on Information and Systems D, vol. 77, pp. 1321-1329, 1994.

[8] P. Milgram, T. Haruo, U. Akira, and K. Fumio, "Augmented reality: a class of displays on the reality-virtuality continuum," in Telemanipulator and Telepresence Technologies, pp. 282-292, 1994.

[9] D. Yu, J. S. Jin, S. Luo, and W. Lai, "A useful visualization technique: a literature review for augmented reality and its application, limitation \& future direction," in Visual Information Communication, M. L. Huang, Q. V. Nguyen, and K. Zhang, Eds., pp. 311-337, Springer, New York, NY, USA, 2010.

[10] Y. Genc, S. Riedel, F. Souvannavong, C. Akinlar, and N. Navab, "Marker-less tracking for AR: a learning-based approach," in Proceedings of the International Symposium on Mixed And Augmented Reality (ISMAR '02), pp. 295-304, IEEE Computer Society, Darmstadt, Germany, 2002.

[11] S. de Buck, F. Maes, J. Ector et al., "An augmented reality system for patient-specific guidance of cardiac catheter ablation procedures," IEEE Transactions on Medical Imaging, vol. 24, no. 11, pp. 1512-1524, 2005.

[12] C. S. Özbek, B. Giesler, and R. Dillmann, "Jedi training: playful evaluation of head-mounted augmented reality display systems," in The Conference Medical Imaging, Proceedings of SPIE, San Diego, Calif, USA, May 2004.

[13] B. Schwald and B. Laval, "An augmented reality system for training and assistance to maintenance in the industrial context," in Proceedings of the International Conference in Central Europe on Computer Graphics, Visualization and Computer Vision, pp. 425-432, University of West Bohemia, Plzen, Czech Republic, 2003.

[14] R. Grasset, X. Decoret, and J. D. Gascuel, "Augmented reality collaborative environment: calibration and interactive science editing," in Proceedings of the Virtual Reality International Conference (VRIC '01), Laval Virtual, 2001.

[15] T. N. Arvanitis, A. Petrou, J. F. Knight et al., "Human factors and qualitative pedagogical evaluation of a mobile augmented reality system for science education used by learners with physical disabilities," Personal and Ubiquitous Computing, vol. 13, no. 3, pp. 243-250, 2009.

[16] L. Kerawalla, R. Luckin, S. Seljeflot, and A. Woolard, “Making it real': exploring the potential of augmented reality for teaching primary school science," Virtual Reality, vol. 10, no. 3-4, pp. 163174, 2006.

[17] Y.-J. Chang, Y.-S. Kang, and P.-C. Huang, "An augmented reality (AR)-based vocational task prompting system for people with cognitive impairments," Research in Developmental Disabilities, vol. 34, no. 10, pp. 3049-3056, 2013.

[18] R. Hervás, J. Bravo, and J. Fontecha, "An assistive navigation system based on augmented reality and context awareness for people with mild cognitive impairments," IEEE Journal of 
Biomedical and Health Informatics, vol. 18, no. 1, pp. 368-374, 2014.

[19] G. A. Assis, A. G. Corrêa, M. B. R. Martins, W. G. Pedrozo, and R. D. Lopes, "An augmented reality system for upper-limb poststroke motor rehabilitation: a feasibility study," Disability and Rehabilitation: Assistive Technology, vol. 4, pp. 1-8, 2014.

[20] A. J. Espay, Y. Baram, A. K. Dwivedi et al., "At-home training with closed-loop augmented-reality cueing device for improving gait in patients with Parkinson disease," Journal of Rehabilitation Research and Development, vol. 47, no. 6, pp. 573-582, 2010.

[21] X. Luo, T. Kline, H. C. Fischer, K. A. Stubblefield, R. V. Kenyon, and D. G. Kamper, "Integration of augmented reality and assistive devices for post-stroke hand opening rehabilitation," in Proceedings of the 27th Annual International Conference of the Engineering in Medicine and Biology Society (EMBS '05), pp. 6855-6858, IEEE, September 2005.

[22] M. Markovic, S. Dosen, C. Cipriani, D. Popovic, and D. Farina, "Stereovision and augmented reality for closed-loop control of grasping in hand prostheses," Journal of Neural Engineering, vol. 11, no. 4, Article ID 046001, 2014.

[23] M. Khademi, H. M. Hondori, L. Dodakian, S. Cramer, and C. V. Lopes, "Comparing 'pick and place' task in spatial augmented reality versus non-immersive virtual reality for rehabilitation setting," in Proceedings of the 35th Annual International Conference of the IEEE Engineering in Medicine and Biology Society (EMBC '13), pp. 4613-4616, 2013.

[24] H. M. Hondori, M. Khademi, L. Dodakian, S. C. Cramer, and C. V. Lopes, "A Spatial Augmented Reality rehab system for poststroke hand rehabilitation," Studies in Health Technology and Informatics, vol. 184, pp. 279-285, 2013.

[25] O. Baus and S. Bouchard, "Moving from virtual reality exposure-based therapy to augmented reality exposure-based therapy: a review," Frontiers in Human Neuroscience, vol. 8, article 112, 2014.

[26] D. Moher, A. Liberati, J. Tetzlaff, D. G. Altman, and P. Grp, "Preferred reporting items for systematic reviews and metaanalyses: the PRISMA statement," PLoS Medicine, vol. 6, no. 7, Article ID e1000097, 2009.

[27] A. P. Association, Diagnostic and Statistical Manual for Mental Disorders (DSM-IV-TR), American Psychiatric Association, American Occupational Therapy, Washington, DC, USA, 4th edition, 2000.

[28] M. Wrzesien, J.-M. Burkhardt, M. A. Raya, and C. Botella, "Mixing psychology and HCI in evaluation of augmented reality mental health technology," in Proceedings of the 29th Annual CHI Conference on Human Factors in Computing Systems (CHI '11), pp. 2119-2124, Vancouver, Canada, May 2011.

[29] M. Wrzesien, J.-M. Burkhardt, M. Alcan iz, and C. Botella, "How technology influences the therapeutic process: a comparative field evaluation of augmented reality and in vivo exposure therapy for phobia of small animals," in Proceedings of the Human-Computer Interaction (INTERACT '11), pp. 523-540, Lisbon, Portugal, 2011.

[30] M. Wrzesien, M. Alcañiz, C. Botella et al., "The therapeutic lamp: treating small-animal phobias," IEEE Computer Graphics and Applications, vol. 33, no. 1, pp. 80-86, 2013.

[31] M. C. Juan, M. Alcañiz, C. Monserrat, C. Botella, R. M. Baños, and B. Guerrero, "Using augmented reality to treat phobias," IEEE Computer Graphics and Applications, vol. 25, no. 6, pp. 3137, 2005.
[32] J. Breton-López, S. Quero, C. Botella, A. García-Palacios, R. M. Baños, and M. Alcañiz, "An augmented reality system validation for the treatment of cockroach phobia," Cyberpsychology, Behavior, and Social Networking, vol. 13, pp. 705-710, 2010.

[33] C. Botella, J. Breton-López, S. Quero et al., “Treating cockroach phobia using a serious game on a mobile phone and augmented reality exposure: a single case study," Computers in Human Behavior, vol. 27, no. 1, pp. 217-227, 2011.

[34] C. Botella, J. Bretón-López, S. Quero, R. Baños, and A. GarcíaPalacios, "Treating cockroach phobia with augmented reality," Behavior Therapy, vol. 41, no. 3, pp. 401-413, 2010.

[35] C. Botella, R. Banos, B. Guerrero, M. Juan, and M. Alcañiz, "Mixing realities? An augmented reality system for the treatment of cockroach phobia," CyberPsychology \& Behavior, vol. 8, pp. 305-306, 2005.

[36] M. C. Juan and D. Prez, "Using augmented and virtual reality for the development of acrophobic scenarios. Comparison of the levels of presence and anxiety," Computers and Graphics, vol. 34, no. 6, pp. 756-766, 2010.

[37] M. C. Juan and J. Calatrava, "An augmented reality system for the treatment of phobia to small animals viewed via an optical see-through HMD. Comparison with a similar system viewed via a video see-through HMD," International Journal of HumanComputer Interaction, vol. 27, no. 5, pp. 436-449, 2011.

[38] M. C. Juan and D. Joele, "A comparative study of the sense of presence and anxiety in an invisible marker versus a marker augmented reality system for the treatment of phobia towards small animals," International Journal of Human Computer Studies, vol. 69, no. 6, pp. 440-453, 2011.

[39] M. C. Juan, C. Botella, M. Alcañiz et al., "An augmented reality system for treating psychological disorders: application to phobia to cockroaches," in Proceedings of the 3rd IEEE/ACM International Symposium on Mixed and Augmented Reality (ISMAR '04), pp. 256-257, IEEE, November 2004.

[40] C. M. Botella, M. C. Juan, R. M. Baños, M. Alcañiz, V. Guillén, and B. Rey, "Mixing realities? An application of augmented reality for the treatment of cockroach phobia," Cyberpsychology \& Behavior, vol. 8, no. 2, pp. 162-171, 2005.

[41] L.-G. Ost, P. M. Salkovskis, and K. Hellstrom, "One-session therapist-directed exposure vs. self-exposure in the treatment of spider phobia," Behavior Therapy, vol. 22, no. 3, pp. 407-422, 1991.

[42] L. G. Öst, Rapid Treatment of Specific Phobias, John Wiley \& Sons, New York, NY, USA, 2000.

[43] M. C. Juan, R. Baños, C. Botella, D. Pérez, M. Alcañiz, and C. Monserrat, "An augmented reality system for the treatment of acrophobia: the sense of presence using immersive photography," Presence: Teleoperators and Virtual Environments, vol. 15, no. 4, pp. 393-402, 2006.

[44] J. Wolpe, The Practice of Behavior Therapy, Pergamon Press, New York, NY, USA, 1969.

[45] I. M. Marks and A. M. Mathews, "Case histories and shorter communication," Behaviour Research and Therapy, vol. 17, pp. 263-267, 1979.

[46] J. Szymanski and W. J. O’Donohue, "Fear of spiders questionnaire," Journal of Behavior Therapy and Experimental Psychiatry, vol. 26, no. 1, pp. 31-34, 1995.

[47] A. Arntz, E. Lavy, G. van Den Berg, and S. van Rijsoort, "Negative beliefs of spider phobics: a psychometric evaluation of the spider phobia beliefs questionnaire," Advances in Behaviour Research and Therapy, vol. 15, no. 4, pp. 257-277, 1993. 
[48] R. M. Ban os, S. Quero, S. Salvador, and C. Botella, The Role of Presence and Reality Judgement in Virtual Environments in Clinical Psychology, Verlag Integrative Psychiatrie, Innsbruck, Austria, 2005.

[49] M. Slater, M. Usoh, and A. Steed, "Depth of presence in virtual environments," Presence: Teleoperators and Virtual Environments, vol. 3, pp. 130-144, 1994.

[50] A. Gorini and G. Riva, "The potential of Virtual Reality as anxiety management tool: a randomized controlled study in a sample of patients affected by generalized anxiety disorder," Trials, vol. 9, article 25, 2008.

[51] T. D. Parsons and A. A. Rizzo, "Affective outcomes of virtual reality exposure therapy for anxiety and specific phobias: a meta-analysis," Journal of Behavior Therapy and Experimental Psychiatry, vol. 39, no. 3, pp. 250-261, 2008.

[52] G. Riva, "Virtual reality in eating disorders and obesity: state of the art and future directions," CyberPsychology \& Behavior, vol. 8, p. 351, 2005.

[53] G. Riva, M. Bacchetta, M. Baruffi, and E. Molinari, "Virtual reality-based multidimensional therapy for the treatment of body image disturbances in obesity: a controlled study," Cyberpsychology and Behavior, vol. 4, no. 4, pp. 511-526, 2001.

[54] A. Rizzo, J. C. Buckwalter, and C. Van der Zaag, "Virtual environment applications in clinical neuropsychology," in The Handbook of Virtual Environments, K. M. Stanney, Ed., pp. 10271064, Erlbaum, New York, NY, USA, 2002.

[55] R. W. Jeffery, L. H. Epstein, G. T. Wilson et al., "Long-term maintenance of weight loss: current status," Health Psychology, vol. 19, no. 1, pp. 5-16, 2000.

[56] T. Mann, A. J. Tomiyama, E. Westling, A.-M. Lew, B. Samuels, and J. Chatman, "Medicare's search for effective obesity treatments. Diets are not the answer," American Psychologist, vol. 62, no. 3, pp. 220-233, 2007.

[57] G. M. Manzoni, G. L. Cesa, D. Villani, G. Castelnuovo, E. Molinari, and G. Riva, "VR-enhanced treatment of anxiety in obese subjects: a follow-up study on trait-anxiety, psychological symptornatology, and generalized self-efficacy," CyberPsychology \& Behavior, vol. 9, pp. 699-700, 2006.

[58] S. Côté and S. Bouchard, "Virtual reality exposure for phobias: a critical review," Journal of Cyber Therapy \& Rehabilitation, vol. 1, no. 1, pp. 75-91, 2008.

[59] F. Pallavicini, A. Gaggioli, S. Raspelli et al., "Interreality for the management and training of psychological stress: study protocol for a randomized controlled trial," Trials, vol. 14, no. 1, article 191, 2013.

[60] A. Gaggioli, G. Pioggia, G. Tartarisco et al., "A system for automatic detection of momentary stress in naturalistic settings," Studies in Health Technology and Informatics, vol. 181, pp. 182186, 2012.

[61] W. Barfield, D. Zeltzer, T. B. Sheridan, and M. Slater, Virtual Environments and Advanced Interface Design, Oxford University Press, Oxford, UK, 1995.

[62] M. Ferrer-García, J. Gutiérrez-Maldonado, A. Caqueo-Urízar, and E. Moreno, "The validity of virtual environments for eliciting emotional responses in patients with eating disorders and in controls," Behavior Modification, vol. 33, no. 6, pp. 830854, 2009.

[63] J. Gutiérrez-Maldonado, M. Ferrer-García, A. Caqueo-Urízar, and A. Letosa-Porta, "Assessment of emotional reactivity produced by exposure to virtual environments in patients with eating disorders," Cyberpsychology and Behavior, vol. 9, no. 5, pp. 507-513, 2006.
[64] A. Gorini, E. Griez, A. Petrova, and G. Riva, "Assessment of the emotional responses produced by exposure to real food, virtual food and photographs of food in patients affected by eating disorders," Annals of General Psychiatry, vol. 9, article 30, 2010. 


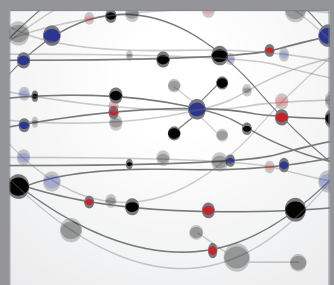

The Scientific World Journal
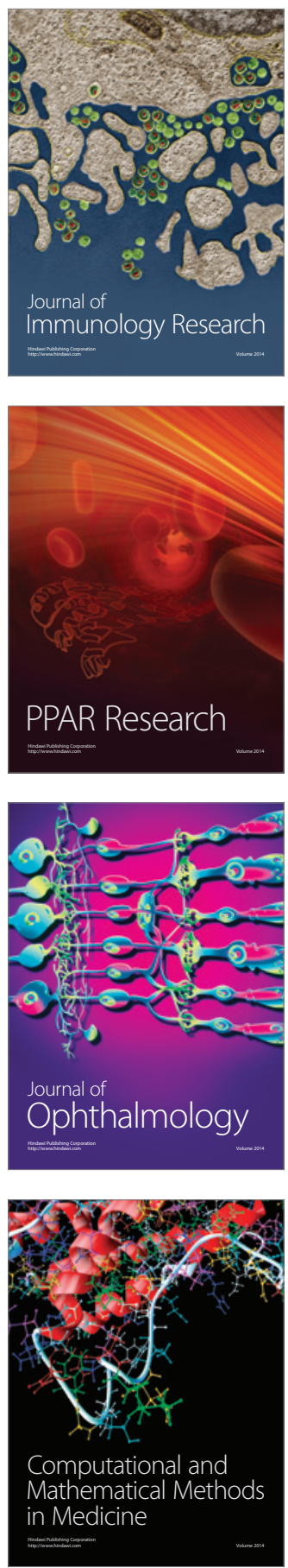

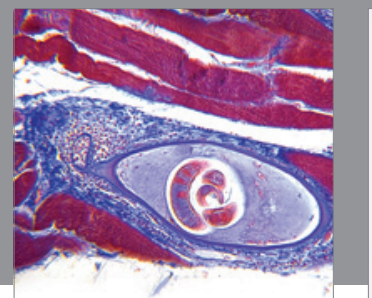

Gastroenterology

Research and Practice
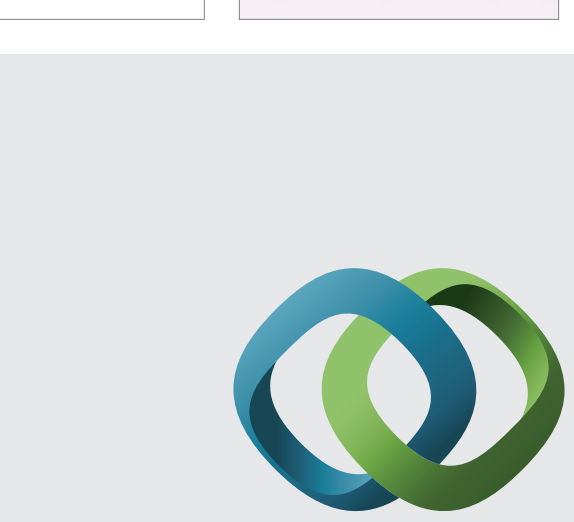

\section{Hindawi}

Submit your manuscripts at

http://www.hindawi.com
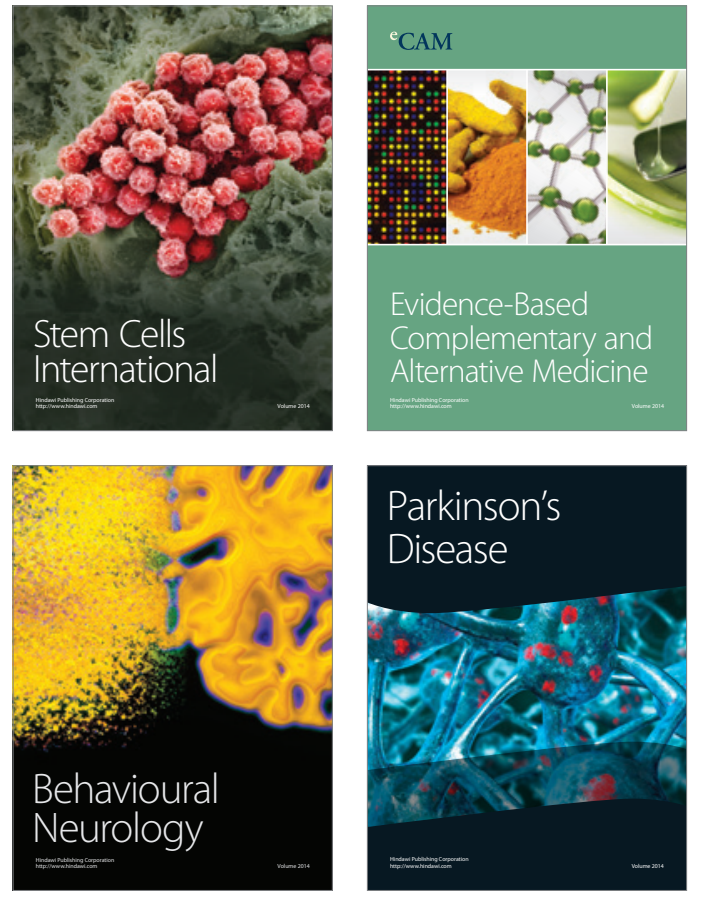
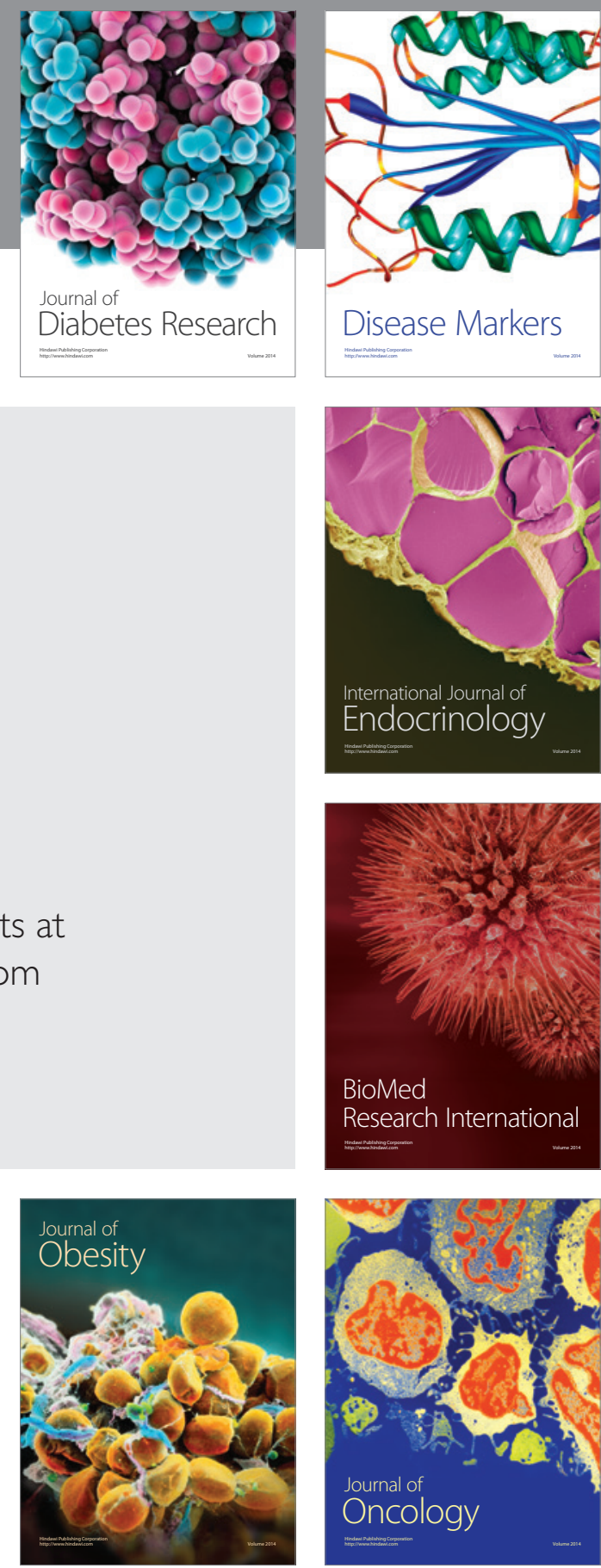

Disease Markers
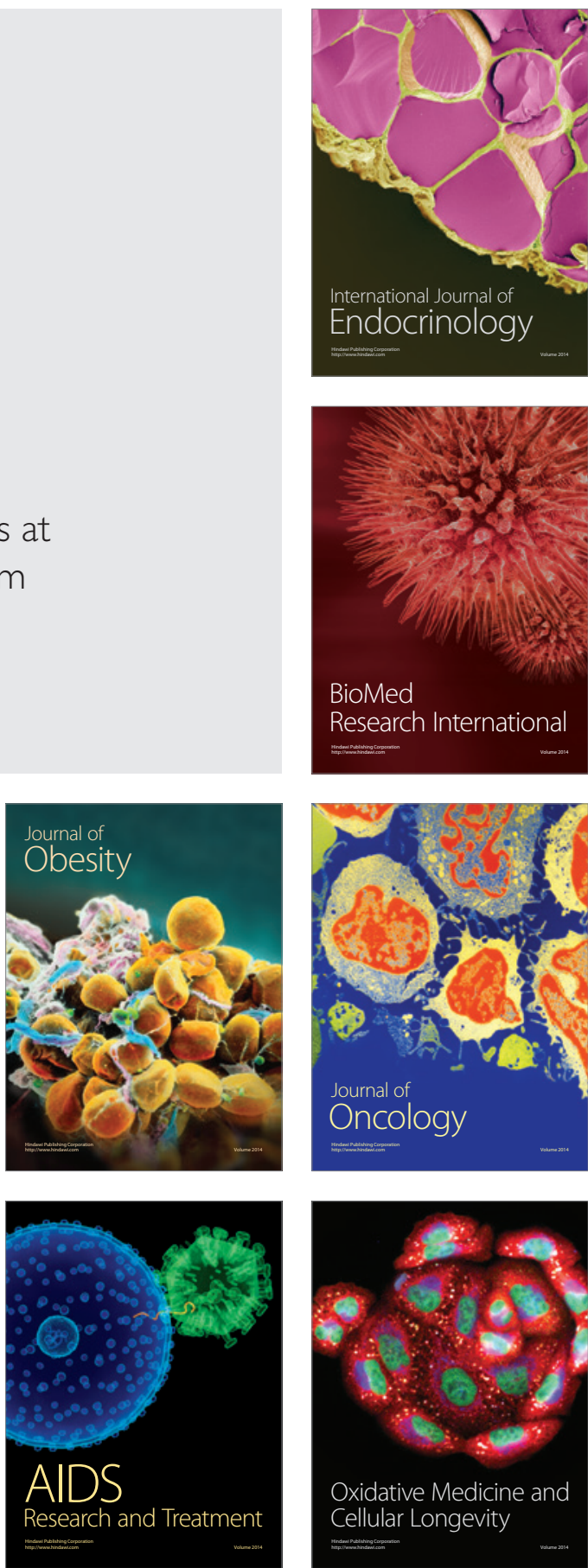